\title{
OPINIÃO CONSULTIVA 26/2020 DA CORTE INTERAMERICANA DE DIREITOS HUMANOS: SUBSISTEM OBRIGAÇÕES INTERNACIONAIS DE DIREITOS HUMANOS AO ESTADO-MEMBRO DA OEA QUE DENUNCIA A CONVENÇÃO AMERICANA DE DIREITOS HUMANOS?
}

\author{
Eneida Orbage de Britto Taquary ${ }^{1}$ \\ Catharina Orbage de Britto Taquary Berino ${ }^{2}$
}

\begin{abstract}
RESUMO: Analisa a opinião consultiva 26/2020, proposta pela Colômbia perante a Corte Interamericana de Direitos Humanos - Corte IDH. A importância do tema se instala no reconhecimento das obrigações internacionais do Estado - membro da Organização dos Estados Americanos - OEA, ainda que denuncie a Convenção Americana de Direitos Humanos - CADH. A problemática refere-se as obrigações que subsistem ao Estado membro da Organização dos Estados Americanos que denuncia a Convenção Americana de Direitos Humanos. Tem por objetivo identificar a natureza jurídica das opiniões consultivas, sua abrangência, e analisar a OC 26/20 da Corte IDH. A metodologia se desenvolve na análise da Opinião Consultiva 26/2020 da Corte IDH.
\end{abstract}

PALAVRAS-CHAVE: Opinião Consultiva 26/2020; Corte interamericana de Direitos Humanos; Obrigações Internacionais; Denúncia; Convenção Americana de Direitos Humanos.

\section{CONSULTATIVE OPINION 26/2020 OF THE INTER-AMERICAN COURT OF HUMAN RIGHTS: INTERNATIONAL HUMAN RIGHTS OBLIGATIONS SUBSISTENT TO THE OAS MEMBER STATE THAT DENOUNCES THE AMERICAN HUMAN RIGHTS CONVENTION?}

1 Eneida Orbage de Britto Taquary é Advogada associada do Escritório de Advocacia Borges Taquary. Delegada de Polícia Aposentada da Polícia Civil do Distrito Federal. Professora Doutora da Faculdade Presbiteriana Mackenzie Brasília-Distrito Federal. Doutora em Direito pelo Centro Universitário de BrasíliaUNICEUB, Mestre em Direito das Relações Internacionais pelo Centro Universitário de Brasília-UNICEUB e Mestre em Direito pela Universidade Católica de Brasília-UCB. Especialista em Segurança Pública, metodologia do ensino superior e Tribunais Superiores. Professora de Direito, com ênfase em Metodologia da pesquisa, Estudo da História do Direito, Direito Penal e Processual Penal, Legislação Penal e processual Penal Especial; Direito Internacional e Direitos humanos e humanitário. Autora dos livros: Crimes Contra os Costumes; Tribunal Penal Internacional e a Emenda Constitucional no 45/2004; Temas de Direito Penal e Direito Processual Penal; Proteção Internacional da Pessoa Humana: sistemas normativos de proteção; Mestre Thompson e outros mestres: edição em homenagem a Paulo Thompson Flores; Vida de Delegada I, Vida de Delegada II, Vida de Delegada III-Assédio.

2 Catharina Orbage de Britto Taquary Berino é advogada, Sócia do Escritório de Advocacia Borges Taquary, Professora Universitária (PhD em Direito), Escritora e Pesquisadora. É Pós-Doutora e Doutora em Direito pelo Centro Universitário de Brasília - CEUB. É Mestre em Direito e Políticas Públicas pelo CEUB e pela Universidad del Litoral de Santa Fe - Argentina. É especialista em Psicologia Jurídica, em Direito Constitucional e em Docência do Ensino Superior, Gestão e Tutoria EAD. É bacharel em Direito pelo CEUB. Foi pesquisadora do Distrito Federal pela Fundação de Apoio à Pesquisa do Distrito Federal FAP/DF e foi bolsista da Coordenação de Aperfeiçoamento de Pessoal de Nível Superior - Capes para o Mestrado em Direito e Políticas Públicas e para o Doutoramento em Direito. É autora dos livros: "A Boa-Fé No Direito Administrativo: A Legítima Expectativa Como Limite à Burocracia" e "O Direito Fundamental à Resolução Pacífica de Conflitos: Psicologia Jurídica, Mediação e Comunicação Não Violenta”. É Diretora do Centro de Pesquisa e membro da Comissão Nacional de Mediação da Associação Brasileira de Advogados - ABA. 
ABSTRACT: Analysis of advisory opinion 26/2020, proposed by Colombia before the InterAmerican Court of Human Rights - Court H.R. Regardless of the issue, it is installed not to reconfirm the international obligations of the State - member of the Organization of American States - OAS, in addition to denouncing to the American Convention of Human Rights - ACHR. The problem refers to the obligations that subsystem the State - member of the Organization of American States that denounces the American Convention of Human Rights. Its objective is to identify the legal nature of advisory opinions, their scope, and to analyze the OC 26/20 - Court H.R. The methodology is developed in the analysis of the Advisory Opinion 26/2020 of the Inter-American Court.

KEYWORDS: Advisory Opinion 26/2020; Inter-American Court of Human Rights; International Obligations; complaint; American Convention on Human Rights.

\section{INTRODUÇÃO}

O artigo tem como objetivo analisar a Opinião Consultiva 26/2020, proposta pela Colômbia perante a Corte Interamericana de Direitos Humanos- Corte IDH, em 06 de maio de 2019, com fundamento no art. 64.1 da Convenção Americana de Direitos Humanos e estabelecido no art. 70.1 e 70.2 do Regulamento, que tem por objeto analisar o alcance das obrigações em matéria de direitos humanos de um Estado que denuncie a Convenção Americana sobre Direitos Humanos e tem interesse em retirar-se da Organização dos Estados Americanos - OEA.

A importância do tema se instala no reconhecimento das obrigações internacionais do Estado-membro da OEA, ainda que denuncie a Convenção Americana de Direitos Humanos $\mathrm{CADH}$.

A problemática refere-se as obrigações que subsistem ao Estado-membro da Organização dos Estados Americanos que denuncia a Convenção Americana de Direitos Humanos.

Dentre os objetivos, se destacam a identificação da natureza jurídica das opiniões consultivas, sua abrangência, e ainda conhecer o conteúdo da Opinião Consultiva 26/2020 decorrente do exercício da competência consultiva da Corte Interamericana de Direitos Humanos - Corte IDH.

A metodologia se desenvolve em primeiro plano, na análise das opiniões consultivas da Corte IDH, e no segundo, na análise da Opinião Consultiva 26/2020, em especial. A Corte IDH já emitiu 26 opiniões consultivas, provenientes de Estados-parte na Convenção American de Direitos Humanos-CADH, destacando-se a Argentina, Chile, Costa Rica, Brasil, México, 
Paraguai, Peru, Uruguai, Panamá e Venezuela, e decorrentes de iniciativas da Comissão Interamericana de Direitos Humanos.

Em várias delas, como a de $\mathrm{n}^{\circ} 5$, que trata da liberdade de expressão; a de $\mathrm{n}^{\circ} 16$ referente à assistência consular; a de $n^{\circ} 17$, que trata da condição jurídica e dos direitos das crianças; a de $n^{\circ} 18$, que versa sobre os imigrantes não documentados e a 21 que trata dos direitos das crianças e adolescentes em situação irregular de imigração a Corte IDH criou Standards de proteção, com efeitos erga omnes, impondo responsabilização aos Estados que violarem tais regras e impondo o dever de reparação. Esses Standards são princípios inafastáveis no Sistema Interamericana de Direitos Humanos e no sistema onusiano.

As opiniões consultivas e os pareceres da Corte IDH denotam que a fase de uma Corte de natureza eminentemente política e desacreditada passou a ser uma Corte com a maior competência consultiva no sistema regional, equivalente às Cortes do sistema da ONU, bem como evidenciou por suas opiniões consultivas o desenvolvimento da jurisprudência da Corte, e ainda a transposição de jurisprudência, adotando mesmo fundamento em questões semelhantes em regiões diversas do planeta, e métodos e princípios de interpretação semelhantes.

Standards foram construídos no âmbito do SIDH, por intermédio das Opiniões Consultivas, quando da fundamentação do parecer emitido, ratificando-se o uso de normas de jus cogens e de efeito erga omnes nas diversas matérias analisadas e aplicando o princípio basilar do direito internacional de harmonização das diversas normas internacionais. Como exemplo o princípio do pacta sund servanda, a boa-fé na interpretação dos tratados, o devido processo legal, não discriminação e igualdade, podendo diferenciar o tratamento de crianças e adolescentes.

\section{A CORTE INTERAMERICANA DE DIREITOS HUMANOS}

Instituída no âmbito da Convenção Americana de Direitos Humanos, tem sua sede em San José da Costa Rica, onde foi instalada a 3 de setembro de 1979, podendo realizar reuniões em qualquer Estado membro da OEA quando a maioria de seus membros considerar conveniente e mediante aprovação do referido Estado. 
É uma instituição autônoma, cujo objetivo é a aplicação e a interpretação da Convenção Americana sobre Direitos Humanos, conforme artigo primeiro de seu estatuto. A Corte Interamericana possui dupla função: consultiva e jurisdicional.

No exercício da função consultiva elabora pareceres acerca de interpretação de quaisquer dispositivos da Convenção, bem como de outros tratados de proteção de direitos humanos nos Estados Americanos, mediante consulta dos Estados-Partes ou na Convenção, ou ainda sobre a compatibilidade entre leis internas do país solicitante e os demais instrumentos internacionais, e relatórios que submeterá à Assembleia Geral da OEA sobre suas atividades do ano anterior e indicará os casos que um Estado-parte não tenha dado cumprimento a suas sentenças.

Poderá ainda celebrar convênios de cooperação com instituições que não tenham fins lucrativos, visando obter colaboração e fortalecer e promover os princípios jurídicos e institucionais da Convenção e da Corte (CORREIA 2008. p.p. 117-133).

No cumprimento da segunda função, a Corte Interamericana de Direitos HumanosCorte IDH, depois de verificados os pressupostos de admissibilidade (esgotados os recursos de jurisdição interna, não haja litispendência, ou coisa julgada, ou seja, não esteja o fato sendo objeto de análise em outra esfera internacional e não tenha decorrido o prazo de seis meses a partir da ciência da decisão que lhe negou acolhimento de sua pretensão), decidirá se houve violação de um direito ou liberdade protegido na Convenção e prolatará uma sentença, determinando a restauração do gozo do direito ou da liberdade violados e a reparação das consequências advindas com a prática do ato violador.

Nos casos de extrema urgência e gravidade, visando evitar a lesão ao direito ou liberdade, poderá examinar a adoção de medidas cautelares, atuando a pedido da Comissão quando o caso ainda não estiver sob sua apreciação (CORREIA 2008. p.p. 117-133).

A competência da Corte em interpretar as cláusulas da $\mathrm{CADH}$ consoante à interpretação sistemática foi objeto da $\mathrm{OC}^{\circ}$ 1, datada de 24 de setembro de 1982. Oriunda da solicitação do governo do Peru versava sobre "otros tratados" objeto de "la función consultiva de la corte", como o art. 64 deveria ser interpretado, se de forma restritiva ou não, em consonância apenas com os tratados de que os Estados Americanos sejam partes (CORTE IDH.2021).

A CIDH em parecer admitiu que era de sua competência tratar da interpretação da $\mathrm{CADH}$ e a interpretação deveria ser feita de forma sistemática, isto é, levando-se em conta 
todos os tratados de direitos humanos, bilaterais ou multilaterais, que os Estados tenham ratificado e, portanto, cumprindo os compromissos internacionais decorrentes da sua celebração, no âmbito regional ou global, desde que afeto ao Estado-parte na CADH e na CIDH. Admitiu o amplo alcance de sua competência consultiva (CORTE IDH.2021).

Também na OC $\mathrm{n}^{\circ}$ 2, datada de 24 de setembro de 1982, oriunda da Comissão IDH tem por objeto "El Efecto de las Reservas sobre la Entrada en Vigencia de la Convención Americana sobre Derechos Humanos" e logo o momento que um Estado passa a fazer parte de uma Convenção, fazendo ou não reservas e se a Convenção de Viena seria aplicada (art. 20) (CORTE IDH.2021).

Em parecer a CIDH entendeu que a "la convención entra en vigencia para un estado que la ratifique o se adhiera a ella con o sin reservas, en la fecha del depósito de su instrumento de ratificación o adhesión", e ainda que o parágrafo 1 do artigo 20 da Convenção de Viena é pertinente aos artigos 74 e 75 da CADH, e o artigo 20, inciso 4, é inaplicável por ser obsoleto (CORTE IDH.2021).

Observe-se que as duas Opiniões consultivas acima mencionadas estão diretamente relacionadas com Opinião Consultiva $n^{\circ}$ 26/2020, proposta pela Colômbia perante a Corte IDH e tem por objeto identificar quais são as obrigações que subsistem ao Estado-parte na Organização dos Estados Americanos-OEA e também na Convenção Americana de Direitos Humanos-CADH que denuncia a CADH e pretende se retirar do sistema da OEA, e os mecanismos de que dispõe a Comunidade Internacional para exigir do Estado o cumprimento de obrigações e os mecanismos de que dispõe o indivíduo para ver seus direitos humanos protegidos.

As indagações acima foram repassadas pela Corte IDH para observações, havendo manifestação da Comissão Interamericana de Direitos Humanos-CIDH, da sociedade civil, dos Estados -membros da OEA: Bolívia, Brasil; Estados Unidos; México; Nicarágua; Panamá; Colômbia e Honduras, além de organismos não governamentais e instituições acadêmicas, no tocante aos três questionamentos.

\section{ALGUMAS OPINIÕES CONSULTIVAS DA CORTE INTERAMERICANA DE DIREITOS HUMANOS}


A CIDH já emitiu 26 opiniões consultivas, provenientes de Estados-parte na CADH, destacando-se a Argentina, Chile, Costa Rica, Brasil, México, Paraguay, Peru, Uruguay e Venezuela, e decorrentes de iniciativas da Comissão Interamericana de Direitos Humanos. Encontra-se pendente de apreciação uma consulta feita pelo governo do Panamá, realizada em 28 de abril de 2014.

Em várias delas, como a de $\mathrm{n}^{\mathrm{o}} 5$, que trata da liberdade de expressão; a de $\mathrm{n}^{\circ} 16$ referente à assistência consular; a de $n^{\circ} 17$, que trata da condição jurídica e dos direitos das crianças; a de $n^{\circ} 18$, que versa sobre os imigrantes não documentados e a 21 que trata dos direitos das crianças e adolescentes em situação irregular de imigração a Corte IDH criou Standards de proteção, com efeitos erga omnes, impondo responsabilização aos Estados que violarem tais regras e impondo o dever de reparação. Esses Standards são princípios inafastáveis no SIDH e no sistema onusiano.

As opiniões consultivas e os pareceres da CIDH denotam que a fase de uma Corte de natureza eminentemente política e desacreditada passou a ser uma Corte com a maior competência consultiva no sistema regional, equivalente às Cortes do sistema da ONU, bem como evidenciou por suas opiniões consultivas o desenvolvimento da jurisprudência da Corte, e ainda a transposição de jurisprudência, adotando mesmo fundamento em questões semelhantes em regiões diversas do planeta, e métodos e princípios de interpretação semelhantes.

Standards foram construídos no âmbito do SIDH, por intermédio das Opiniões Consultivas, quando da fundamentação do parecer emitido, ratificando-se o uso de normas de jus cogens e de efeito erga omnes nas diversas matérias analisadas e aplicando o princípio basilar do direito internacional de harmonização das diversas normas internacionais. Como exemplo o princípio do pacta sund servanda, a boa-fé na interpretação dos tratados, o devido processo legal, não discriminação e igualdade, podendo diferenciar o tratamento de crianças e adolescentes, conforme analise abaixo.

A competência da Corte em interpretar as cláusulas da $\mathrm{CADH}$ consoante à interpretação sistemática foi objeto da $\mathrm{OC} \mathrm{n}^{\circ}$ 1, datada de 24 de setembro de 1982. Oriunda da solicitação do governo do Peru versava sobre "otros tratados" objeto de "la función consultiva de la corte", como o art. 64 deveria ser interpretado, se de forma restritiva ou não, em consonância apenas com os tratados de que os Estados Americanos sejam partes. 
A CIDH em parecer admitiu que era de sua competência tratar da interpretação da $\mathrm{CADH}$ e a interpretação deveria ser feita de forma sistemática, isto é levando-se em conta todos os tratados de direitos humanos, bilaterais ou multilaterais, que os Estados tenham ratificado e portanto cumprindo os compromissos internacionais decorrentes da sua celebração, no âmbito regional ou global, desde que afeto ao Estado-parte na CADH e na CIDH. Admitiu o amplo alcance de sua competência consultiva.

A OC n ${ }^{\circ}$ 2, datada de 24 de setembro de 1982, oriunda da Comissão IDH tem por objeto "El Efecto de las Reservas sobre la Entrada en Vigencia de la Convención Americana sobre Derechos Humanos" e logo o momento que um Estado passa a fazer parte de uma Convenção, fazendo ou não reservas e se a Convenção de Viena seria aplicada (art. 20).

Em parecer a CIDH entendeu que a "la convención entra en vigencia para un estado que la ratifique o se adhiera a ella con o sin reservas, en la fecha del depósito de su instrumento de ratificación o adhesión", e ainda que o parágrafo 1 do artigo 20 da Convenção de Viena é pertinente aos artigos 74 e 75 da CADH, e o artigo 20, inciso 4, é inaplicável por ser obsoleto.

A OC $n^{\circ}$ 3, datada de 8 de setembro de 1983 também foi oriunda de solicitação da Comissão IDH, acerca das restricciones a la Pena de Muerte (Arts. 4.2 y 4.4 Convención Americana sobre Derechos Humanos), ou da interpretação do segundo parágrafo do artigo 4 da $\mathrm{CADH}$, em face de divergências existentes com o governo da Guatemala, em relação a pena de morte, que havia ratificado a $\mathrm{CADH}$, mas havia feito reservas ao dispositivo mencionado.

O objeto restringia-se, em tese, a aplicação da pena de morte a crimes conexos aos crimes políticos na Guatemala. Nesse Estado era proscrita a pena de morte aos crimes políticos.

Em parecer a CIDH esclareceu que era proscrito legislar, após a ratificação da CADH sobre a imposição de pena de morte, bem como a aplicação extensiva dessa pena a crimes conexos, que não estivessem previstos na legislação de um Estado-parte, em face da necessidade de supressão dessa pena.

A OC $\mathrm{n}^{\circ}$ 4, datada de 19 de janeiro de 1984 , postulada pelo Governo da Costa Rica, figura entre as mais importantes no sistema global e regional de proteção dos direitos humanos, em face de três justificativas: 
a) a primeira porque o Estado-parte na $\mathrm{CADH}$ ao modificar sua constituição, visando à redução de direitos ou a criação de exigências antes inexistentes, confirmando a competência exclusiva da Corte para examinar pedido de apreciação e compatibilidade de legislação, como Emendas à Constituição com a CADH e competência exclusiva dos Estadospartes para submeter a solicitação;

b) a segunda porque a CIDH entendeu que o maior rigor nas exigências de aquisição de nacionalidade por naturalização não caracterizava supressão de direitos e a terceira que não haveria discriminação em face do governo costariquenho conceder nacionalidade por naturalização preferencialmente aos "centroamericanos, iberoamericanos y españoles, frente a los demás extranjeros", bem como a preferência "a los centroamericanos, iberoamericanos y españoles por nacimiento"; e ainda que "sí constituye discriminación incompatible con los artículos 17.4 y 24 de la convención estipular en el artículo 14.4 del proyecto condiciones preferentes para la naturalización por causa de matrimonio a favor uno sólo de los cónyuges";

c) e por fim o terceiro, a adoção da teoria da margem de apreciação ou de controle, baseando-se na jurisprudência da CEDH que foi precussora na adoção de tal doutrina.

O parecer da CIDH foi fundamentado no art. 64, $\S 2^{\circ}$ do seu estatuto e ainda no art. 29 da $\mathrm{CADH}$, referentes à sua competência consultiva, e no mérito da questão, o direito à nacionalidade, foram arguídos como fundamentos os arts. 20 da CADH, 19 da Declaração Americana de Direito e Deveres do Homem, e o art. 15 da Declaração Universal dos Direitos Humanos, definindo a nacionalidade como o "el vínculo jurídico político que liga a una persona con un Estado determinado por medio del cual se obliga con él con relaciones de lealtad y fidelidad y se hace acreedor a su protección diplomática".

A CIDH admite que o direito a nacionalidade como direito humano está protegido pelos sistemas universal e regional, devendo o Estado está atendo a essas normas superiores garantidoras da proteção e com elas não conflituarem, apesar de admitir que o Estado é o que mais condições tem de avaliar os requisitos condições de aquisição de nacionalidade por naturalização, de forma a "assegurar a existência de uma ligação efetiva entre aquele que requer a naturalização e os sistemas de valores e interesses da sociedade com o qual ele busca associar-se plenamente". Apesar de admitir que as normas de direitos humanos são hierarquicamente superiores às outras, reconhece que existem temas, como a nacionalidade, que são reservados ao domínio exclusivo da jurisdição doméstica. 
Outro aspecto do parecer da CIDH refere-se ao direito a igualdade de tratamento que se afigura como uma das vertentes da dignidade da pessoa humana e, portanto, não suscetível de atribuição de direitos diferenciados a um grupo como superior a outro. Para a CIDH "tales procedimientos pueden llegar a ser vehículo para juicios subjetivos y arbitrarios, y a constituir instrumentos de políticas discriminatorias que, aunque no se desprendan directamente de la ley, podrían producirse como consecuencia de su aplicación”.

A discriminação estaria expressa no $\S 4^{\circ}$, do artigo 14 da Emenda Constitucional Costarriquenha que estabelece condições especiais de obtenção da nacionalidade a mulher estrangeira que se case com costarriquenho, ressaltando a discriminação de gênero, sob os fundamentos ultrapassados do pátrio poder em relação aos filhos menores, a autoridade marital de fixar o domicílio conjugal e administrar os bens do casal, todos amparados sob o princípio da unidade familiar, que fora rechaçado pela Corte ao estabelecer no artigo 17 (4) da $\mathrm{CADH}$, que os Estados-partes "deben tomar medidas apropiadas para asegurar la igualdad de derechos y la adecuada equivalencia de responsabilidades de los cónyuges en cuanto al matrimonio, durante el matrimonio y en caso de disolución del mismo", assegurando sempre a proteção aos filhos, sobre a base de interesse e conveniência deles.

A OC $n^{\circ} 5$, datada de 13 de novembro de 1985 , oriunda de solicitação da Costa Rica, versava sobre a interpretação dos arts 13 e 29 da $\mathrm{CADH}$, com relação à obrigatoriedade de sindicalização de jornalistas e a liberdade de pensamento e de expressão.

No parecer a CIDH diferencia a dimensão individual e a dimensão social da liberdade de expressão e de pensamento que devem ser garantidas simultaneamente. Na dimensão individual o direito não se circunscreve a liberdade de falar ou de escrever, mas também o difundir o pensamento e fazê-lo chegar ao maior número de pessoas. Na dimensão social, a liberdade de pensar e de expressar seu pensamento é um meio para o intercâmbio de ideias e informações e comunicação de massa entre os seres humanos, sendo repudiada toda censura prévia e mecanismo de controle prévio da opinião ou da informação. $\mathrm{O}$ acesso à informação e a opinião de outrem é tão importante para o cidadão, para a formação da sua própria opinião e da sua transmissão.

Há violação do direito a liberdade de pensar e manifestar seu pensamento quando somente jornalistas sindicalizados ou pessoas sindicalizadas podem exercer sua profissão e logo manifestar seu pensamento, por meio de mecanismos de comunicação de massa, e que os argumentos de que a associação obrigatória reflete fins de utilidade coletiva, bem comum, 
ordem pública, segurança pública ou saúde pública ou vinculados á ética e a responsabilidade profissional e são garantidores de independência dos jornalistas frente a seus empregadores não devem prosperar.

A limitação à liberdade de pensamento e de expressão somente poderá ocorrer em casos previamente previstos e definidos de responsabilidades em decorrência de abusos cometidos e que tais limitações sejam necessárias a atingir os fins de um Estado democrático e preservar suas instituições democráticas, alcançando também os objetivos da CADH, qual seja o de "consolidar, en este Continente, dentro del cuadro de las instituciones democráticas, un régimen de libertad personal y de justicia social, fundado en el respeto de los derechos esenciales del hombre".

$\mathrm{Na}$ OC n ${ }^{\circ}$ 6, datada de 9 de maio de 1986, a CIDH, tem por objeto "La Expresión "Leyes" en el Artículo 30 de la Convención Americana sobre Derechos Humanos", solicitada pelo governo do Uruguai.

Em parecer a $\mathrm{CIDH}$ entende que o direito de resposta deve estar previsto na legislação do Estado-parte a $\mathrm{CADH}$ e se isso não ocorre deve ele editar leis nesse sentido. $\mathrm{O}$ sentido de lei está adstrito ao sistema adotado pelo Estado-parte na $\mathrm{CADH}$, seja de origem da Common Law ou romanista, mas guardadas algumas características como a de nenhuma restrição a direitos humanos poderá ser feita sem observância do princípio da legalidade e da reserva da lei; que tais princípios isolados não efetivam direitos, sendo necessário que se efetive, com a legislação e por intermédio dela , um sistema de mecanismos que efetivem tais direitos. Há necessidade se se construir um sistema formal e material para que se efetivem os direitos previstos na $\mathrm{CADH}$, bem como um órgão de controle sobre essa efetividade; e por fim que deve ser observado o interesse geral e os fins a que ela se presta.

A interpretação da expressão lei prevista no art. 30 da $\mathrm{CADH}$, não significa qualquer lei. "El vocablo leyes cobra todo su sentido lógico e histórico si se le considera como una exigencia de la necesaria limitación a la interferencia del poder público en la esfera de los derechos y libertades de la persona humana". Para efeitos da CADH é considerada "sólo las reglas de derecho que han recibido aprobación legislativa y promulgación ejecutiva pueden ser objeto de opinión consultiva obligatoria".

Uma norma jurídica é, portanto, uma norma adotada por um órgão legislativo e promulgada pelo Poder Executivo, segundo procedimento legislativo previsto na jurisdição de cada Estado, visando o interesse geral e bem comum, e decorrentes do "ejercicio efectivo de 
la democracia representativa", que se traduce, inter alia, en la elección popular de los órganos de creación jurídica, el respeto a la participación de las minorías y la ordenación al bien común” que permitam "la protección de los derechos esenciales del hombre y la creación de circunstancias que le permitan progresar espiritual y materialmente y alcanzar la felicidad" ("Declaración Americana de los Derechos y Deberes del Hombre" .

Em relação à $\mathrm{OC} \mathrm{n}^{\circ}$ 7, 29 de agosto de 1986, proposta pelo Governo da Costa Rica, que solicita a interpretação e alcance do art. 14.1 e dos artigos 1.1. e 2 da CADH, evidenciando o direito de resposta em caso de violação, e a necessidade de lei que trata da matéria, visando a proteção do direito humano.

Em parecer a CIDH, entende que as disposições questionadas devem ser interpretadas de boa-fé e, portanto deve ser assegurada uma resposta igualmente proporcional ao dano causado a vítima da ofensa. Nesse sentido faz remissão à OC. nº5/85 que trata da associação obrigatória dos jornalistas, bem como dos seus fundamentos, inclusive o de que a lei deve garantir o direito de pensamento e expressão por meio do acesso a informação pelos meios de comunicação de massa, e em caso de abuso as responsabilidades devem ser estabelecidas ou observadas as previstas, sempre levando em conta o interesse público e o bem comum, como definidos também na OC mencionada.

A CADH se aplica incondicionalmente aos Estados, ainda que ela faça referência à legislação nacional, ocasião em que o Estado-parte deverá observar o procedimento legislativo para editar lei sobre a matéria.

A OC $n^{\circ}$ 8, de 30 de janeiro de 1987, solicitada pela Comissão IDH, que versa sobre a impossibilidade de suspensão do habeas corpus e recursos de amparo, em estados de exceção, e a interpretação que deve ser dada ao art. 27.2 da CADH, por estarem as garantias ligadas ao Estado de Direito e a democracia.

Em parecer a Corte reafirma a necessidade de observância para interpretação de uma cláusula da CADH da Convenção de Viena sobre o Direito dos Tratados, em especial do art. 26 que estabelece que as obrigações assumidas pelos Estados-partes no Tratado devem ser cumpridas (pacta sunt servanda) e que devem ser cumpridas de boa-fé no tocante a cláusula que prevê a possibilidade de suspensão de garantias em períodos de guerra, de perigo para a segurança pública ou para o Estado Democrático.

Ratifica que a suspensão de direitos caracteriza uma situação excepcional e que poderá caracterizar como uma afronta ao Estado Constitucional, carecendo de legalidade e 
alguns procedimentos judiciais são indispensáveis para garantir a plenitude do exercício dos direitos e liberdades previstos na $\mathrm{CADH}$.

Em especial o habeas corpus e recursos de amparo figuram dentre os procedimentos que não admitem suspensão segundo a cláusula 27.2, porque ele visa garantir o direito à vida. Argumenta que em casos de emergência pública e para preservar os valores maiores de uma sociedade democrática a suspensão de garantias poderia ser a única forma viável. Mas reconhece que a suspensão de garantias não pode ser desvinculada do exercício da democracia participativa, em especial nos países do Hemisfério Sul em que abusos nesse sentido já foram praticados, inclusive por autoridades estatais no exercício de suas funções.

A CIDH fundamenta ainda seu parecer no sentido de que o princípio da legalidade é inseparável das constituições democráticas e do Estado de Direito, conforme manifestação na OC 6/1986, que tratou da expressão leis no ar. 30 da $\mathrm{CADH}$, e, portanto os procedimentos jurídicos estabelecidos nos arts. 25.1 e 7.6 da $\mathrm{CADH}$ "no pueden ser suspendidos conforme al artículo 27.2 de la misma, porque constituyen garantías judiciales indispensables para proteger derechos y libertades que tampoco pueden suspenderse según la misma disposición".

A OC $\mathrm{n}^{\circ}$ 9, datada de 6 de outubro de 1987, solicitada pelo governo do Uruguai, tem objeto semelhante á $\mathrm{OC} \mathrm{n}^{\mathrm{o}} 8$, porque trata do "alcance dela prohibición de suspender las garantías judiciales indispensables para la protección de los derechos mencionados en el artículo 27.2 de la convención".

No parecer, a CIDH adota os mesmos fundamentos utilizados na OC. $\mathrm{N}^{\circ} 08$, de 30 de janeiro de 1987, "que deben considerarse como garantías judiciales indispensables no susceptibles de suspensión, según el artículo 27.2, el hábeas corpus (artículo 7.6), el amparo (artículo 25.1)" e ainda "debe considerarse como garantías judiciales indispensables que no pueden suspenderse, aquellos procedimientos judiciales, inherentes a la forma democrática representativa de gobierno".

A OC $\mathrm{n}^{\circ} 10$, datada de 14 de julho de 1989, solicitada pela Colombia e cujo objeto é a interpretação do artigo 64 da $\mathrm{CADH}$, em relação à Declaração Americana de Direitos e Deveres do Homem.

A CIDH inicialmente considera, em seu parecer, que a Declaração Americana de Direitos e Deveres do Homem, não é um tratado, mas uma resolução adotada por uma 
conferência, e o conceito de tratado deve ser extraído da Convenção de Viena sobre Direito dos Tratados, aos quais os países signatários devem obediência.

Mas o fato de não ser um tratado, não há óbices quanto a interpretação da Declaração Americana de Direitos e Deveres do Homem realizada pela CIDH, em razão do disposto no art. 64.1, da CADH que dispõe sobre a competência da Corte para emitir opiniões consultivas "acerca de la interpretación de los derechos humanos en los estados americanos".

Admite que a interpretação da $\mathrm{CADH}$, da Declaração Americana de Direitos e Deveres do Homem, a Carta da OEA e outros tratados que versem sobre direitos Humanos nos Estados Americanos deve ser sistemática e de forma a proporcionar interação e integração entre os vários documentos, que intrinsecamente possuem os mesmos valores e princípios. Inclui no conceito de tratados que versem sobre direitos humanos a Convenção de Viena sobre Direito dos Tratados de 1969 e a Convenção de Viena sobre Direitos dos Tratados entre Estados e Organizações Internacionais ou entre Organizações Internacionais de 1986.

A OC $\mathrm{n}^{\circ} 11$, datada de 10 de agosto de 1990, versa sobre a regra de esgotamento de recursos no âmbito da jurisdição doméstica como requisito de admissibilidade de petições perante CIDH, consoante os arts 46.1 e 46.2, solicitada pela Comissão IDH, em face de uma pessoa hipossuficiente que não é capaz de fazer uso dos recursos jurídicos do país e se dispensado esse requisito, quais os critérios a serem adotados.

A CADH exige no art. 46 como requisito de admissibilidade perante CIDH o esgotamento dos recursos internos, mas excepciona a regra em três situações: não exista na legislação interna o princípio do devido processo legal, haja demora demasiada e desproporcional na atuação do Estado e não seja permitido o acesso à Justiça.

Em caso de indigentes, termo utilizado pela $\mathrm{CADH}$, o artigo 46.2, estabelece que o fato não implica ausência de necessidade em esgotar internamente os recursos internos, prestigiando os artigos 1.1, 24 e 8, que estabelecem o direito à igualdade, a não discriminação por razões econômicas e o direito de ser ouvido, ou acesso a Justiça.

O esgotamento interno dos recursos como requisito de admissibilidade perante a CIDH não poderá ser exigido se a pessoa, por razões de indulgência, não tiver acesso a justiça ou ainda se seus advogados, por temor generalizado, não possam representar a vítima.

A solicitação realizada pela Costa Rica, na $\mathrm{OC}^{\circ} 12$, datada de 06 de dezembro de 1991, não foi respondida. Versava sobre a compatibilidade entre um projeto de lei que modificava o Código de Processo Penal e a criação de um Tribunal Superior de Cassação 
Penal, cujo projeto tramitava na assembleia legislativa, e o art. 8.2 da CADH, que trata da presunção de não culpabilidade e das garantias processuais mínimas no decorrer do processo crime.

O governo do Uruguay interviu porque considerou que a solicitação não cumpria o disposto no artigo 64.2 da $\mathrm{CADH}$; porque não se tratava de interpretação de lei e sim de projeto de lei e que na $\mathrm{OC} \mathrm{n}^{\circ} 6$, a CIDH havia considerado que somente as leis, aprovadas e promulgadas poderiam ser objeto de opinião consultiva de caráter obrigatório, motivando contestação da Costa Rica, que alegou não haver contradição com os fundamentos da $\mathrm{OC} \mathrm{n}^{\circ}$ 4.

Em parecer a CIDH entendeu que não poderia emitir opinião porque não se tratava de lei, mas projeto de lei, infringindo o disposto no art. 64.2 da $\mathrm{CADH}$, e ainda que a opinião pudesse prejudicar a decisão a ser proferida em casos submetidos à Corte, bem como a defesa da vítima.

A OC $\mathrm{n}^{\circ} 13$, datada de 16 de julho de 1993, solicitada pelos governos da Argentina e do Uruguai, versa sobre a interpretação dos artigos 41, 42, 44, 46, 47, 50 e 51 da CADH e a regularidade jurídica de leis internas, adotadas de acordo com o que dispõe a Constituição, no tocante a sua razoabilidade, conveniência e autenticidade, e, portanto, se o disposto em uma norma do ordenamento jurídico estatal é violadora da $\mathrm{CADH}$, e não se as cláusulas da CADH são contraditórias ao ordenamento jurídico do Estado. Cabe ao Estado conformar seu ordenamento jurídico às obrigações assumidas no âmbito de um tratado, por força do dever que decorre da ratificação.

A CIDH entende que para analisar a compatibilidade entre uma lei e a $\mathrm{CADH}$, se devem examinar os termos razoabilidade, conveniência e autenticidade e ainda a linguagem utilizada na $\mathrm{CADH}$ e na legislação interna. Os critérios de qualificação de uma norma como razoável, conveniente e autêntica devem nortear a interpretação de uma lei frente à CADH.

A razoabilidade é utilizada como parâmetro de interpretação dos tratados e equivalente ao justo, a proporcionalidade e a equidade, com conteúdo de caráter axiológico. A conveniência tem caráter subjetivo na interpretação, mas devem ser observadas as normas da Convenção de Viena sobre o Direito dos Tratados, como o cumprimento das obrigações assumidas. A autenticidade de uma lei deve vincular-se a credibilidade frente a sociedade. Deve ter fé pública, isto é gozar da confiabilidade de atingir aos fins propostos na CADH, que 
se associa a intepretação baseada na boa-fé. Portanto, a fé pública estaria associada a interpretação das cláusulas convencionais de boa-fé.

A CIDH no parecer afirma ser a responsabilidade internacional do Estado decorrente de uma lei que não se conforma com as obrigações assumidas na $\mathrm{CADH}$ ou não se revela razoável com o contexto dela, podendo ser responsabilizado por descumprimento de outras obrigações no sistema global.

A OC $\mathrm{n}^{\circ} 14$, datada de 1994, foi solicitada pela Comissão IDH, tem por objeto a responsabilidade internacional do Estado-parte na $\mathrm{CADH}$, pela edição de lei que manifestamente contrarie as obrigações assumidas no tratado, decorrendo desta contrariedade violações de direitos e liberdades. Essa solicitação decorreu em razão da Constituição do Peru ter disciplinado a incidência de pena de morte para outras hipóteses não previstas. Observe-se que a pena de morte fora discutida na $\mathrm{OC}^{\circ} 3 / 83$, e a CIDH manifestou-se quanto a supressão da referida pena.

A solicitação também recai sobre a responsabilidade dos funcionários ou agentes estatais no cumprimento da lei e consequentemente na violação de direitos, e a interpretação dos artigos 3 e 4 da $\mathrm{CADH}$.

Em parecer a CIDH afirma que a pena de morte está vinculada ao princípio da anterioridade, somente podendo ser aplicada aos casos previstos anteriormente à ratificação da $\mathrm{CADH}$, não podendo o Estado inovar constitucionalmente, criando novas modalidades de imposição de pena de morte, sob pena de reponsabilidade internacional. Nos Estados em que tenha sido abolida não poderá ser renovada para novos crimes.

Admite ainda que os agentes públicos que apliquem a lei manifestamente contrária a CADH poderão dar ensejo à responsabilização do Estado e ainda assumir a responsabilidade individual de caráter penal, se o fato caracterizar crime internacional.

No tocante ao conceito de lei, a CIDH a entende em seu sentido material ou formal. Esse conceito foi discutido exaustivamente pelo referenciado órgão na OC. nº, de 1986, e que tal legislação poderá ser objeto de recomendação para ser modificada, revogando-se ou derrogando-se.

Observe-se que Comissão não tem competência para solicitar opiniões acerca da compatibilidade da legislação interna de um Estado com a Convenção, que segundo a Carta da OEA, cabe aos Estados membros da organização. Carece competência subjetiva para a 
Comissão, isto legitimidade para iniciar a discussão sobre a compatibilidade de uma lei de determinado Estado e a CADH.

A OC $\mathrm{n}^{\circ} 15$, datada de 14 de novembro de 1997, solicitada pelo governo do Chile, que tinha por objeto a possibilidade da CIDH modificar uma opinião, conclusão ou recomendação enviada ao Estado, emitindo um novo informe.

Em parecer, a CIDH sustenta sua decisão nos princípios da boa-fé e da segurança jurídica, ao estabelecer que o referido órgão não está respaldado pela $\mathrm{CADH}$ a emitir opiniões motu próprio e por consequência não poderá modificar opiniões, conclusões e recomendações enviadas aos Estados, e que tenham sido objeto de publicação, salvo se fatos novos ocorrerem e que modifique substancialmente as comunicações anteriores.

A elaboração de um informe e a sua notificação ao Estado gera direitos e obrigações para ambas às partes, motivo pelo qual a alteração injustificada fere a segurança jurídica, reforçado pelo fato de que não existem na $\mathrm{CADH}$ os termos preliminar e definitivo, como atributos do mesmo.

Ficou assentado ainda no parecer que a modificação de uma opinião, recomendação ou informe somente poderá ocorrer se "las partes interesadas, antes de la publicación del propio informe, dentro de plazo establecido. En tal hipótesis se les otorgará alas partes oportunidad de debatir sobre los hechos o errores que motivaron su petición. Bajo ninguna circunstancia la comisión está facultada por la convención para emitir un tercer informe”.

A opinião consultiva referenciada foi importante para todo o SIDH e os Estadosparte porque destacou a necessidade de observância de prazos pela Comissão e pela Corte Interamericana de direitos humanos, em especial quando há várias comunicações envolvendo o mesmo fato, como ocorreu no caso Cayara vs. Peru, onde várias denúncias foram realizadas e apreciadas pela CIDH (denúncias $n^{\circ} 10.264, n^{\circ} 10.206$, no 10.276 e $n^{\circ} 10.446$ ), ensejando vários informes, que foram objeto do caso contencioso citado. As exceções preliminares acabaram por beneficiar o governo do Peru, que teve sua pretensão acolhida, com fundamento na preclusão do direito das vítimas, onde a Corte manifestou-se no sentido de que a Comissão havia submetido o caso a Corte intempestivamente, ocasionando sua decadência, e a missão da Corte deveria ser preservada, guardando "un justo equilibrio entre la protección de los derechos humanos, fin último del sistema, y la seguridad jurídica y equidad procesal que aseguran la estabilidad y confiabilidad de la tutela internacional". 


\section{OPINIÃO CONSULTIVA 26/2020 DA CORTE INTERAMERICANA DE DIREITOS HUMANOS}

A Opinião Consultiva 26/2020 se reveste de grande importância porque ratifica o exposto e consolidado entendimento da Corte IDH, na OC 01/82, que impõe a interpretação sistemática de tratados de direitos humanos, celebrados no sistema global ou regional, isto é, levando-se em conta todos os tratados de direitos humanos, bilaterais ou multilaterais, que os Estados tenham ratificado e, portanto, cumprindo os compromissos internacionais decorrentes da sua celebração, no âmbito regional ou global, desde que afeto ao Estado-parte na CADH e na CIDH.

Como já mencionado a questão principal se refere a três questionamentos realizados pelo Estado Colombiano. São elas:

1-A luz do direito internacional, convencional e consuetudinário, e em especial, a Declaração Americana de Direitos e Deveres do Homem de 1948, quais são as obrigações em matéria de direitos humanos que tem um Estado-membro da OEA que denunciou a CADH?

2-Quais são os efeitos sobre as obrigações em matéria de direitos humanos que subsistem caso o referido Estado também denuncie a Carta da Organização dos Estados americanos e procuram retirar-se da Organização?

3-Quais os mecanismos de que dispõe a Comunidade Internacional, em especial os Estados-membros da OEA, para exigir o cumprimento das obrigações, e de outro lado, os indivíduos sujeitos à jurisdição do Estado de exigir a proteção de seus direitos humanos, quando surge um quadro de graves e sistemáticas violações de direitos?

A manifestação da Comissão Interamericana de Direitos Humanos-CIDH teve inicialmente por objeto a vontade dos Estados em edificar um sistema, por intermédio da Organização dos Estados Americanos (OEA) em 1948, com objetivo de "consolidar neste Continente, no âmbito das instituições democráticas, um regime de liberdade individual e justiça social, fundado no respeito pelos direitos essenciais do homem (CORTE IDH.2021)".

Os Estados-membros da OEA “constituem a garantia coletiva desse sistema. Tendo isso em mente, a Comissão observa, em uma perspectiva preliminar, que os cenários apresentados neste pedido de parecer consultivo são extremamente preocupantes (CORTE IDH.2021)". 
Em relação às questões levantadas pelo Estado Colombiano, a Comissão entendeu que deveria esclarecer que os questionamentos são abstratos, mas que as respostas seriam importantes para nortear o posicionamento futuro dos Estados-membros da OEA e ainda partes na $\mathrm{CADH}$.

Utilizou ainda o argumento de que a universalização dos tratados que contêm obrigações de direitos humanos é uma aspiração legítima do sistema interamericano, que o ser humano é o centro de proteção do sistema interamericano de direitos humanos e que a interpretação normativa deve levar em conta o princípio pro persona estabelecido e reconhecido pelos órgãos do sistema interamericano.

No tocante ao questionamento que versa sobre as obrigações em matéria de direitos humanos que tem um Estado-membro da OEA que denunciou a $\mathrm{CADH}$, a luz do direito internacional, convencional e consuetudinário, e em especial, a Declaração Americana de Direitos e Deveres do Homem de 1948-DADDH, a CIDH fundamentou sua posição no sentido de que o instrumento é fonte de obrigações acordos internacionais para todos os Estados membros da OEA, conforme estabelecido no tratado constitutivo que deu origem à Organização. E que apesar de não ter a formalização e um tratado internacional, a seu significado durante toda a sua evolução extrapolou esta necessidade de forma (CORTE IDH.2021).

O sistema convencional, que contém os direitos humanos, não é a fonte exclusiva do Sistema Interamericano, mas encontra sua fonte também em diversos tratados formalizados no âmbito do sistema e ainda outras competências para a Comissão e a Corte, e outros órgãos da OEA, que fazem parte do sistema internacional americano.

A CIDH convalida seu entendimento de que a denúncia da Convenção Americana não a afeta obrigações internacionais de direitos humanos, decorrentes da CADH, bem como de outros tratados internacionais de direitos humanos que o Estado seja parte e se encontrem em vigor.

Aliado a esse fato, a CIDH preserva suas competências para "conocer peticiones individuales e n conformidad con los artículos 51 y 52 de su Reglamento, y medidas cautelares, según lo establecido en el a rtículo 25 del mismo instrumento (CORTE IDH.2021)". E ainda com base no art. 106 da Carta da OEA, que a CIDH também mantém suas competências de monitoramento e cooperação técnica em matéria de direitos humanos, "relacionadas con la realización de visitas in loco; inclusión del Estado denunciante en su 
Informe Anual y otros informes establecido; convocatoria del Estado denunciante a audiencias, todas ellas establecidas en los capítulos IV, Vy VI del Reglamento de la Comisión (CORTE IDH.2021)".

Em relação aos efeitos sobre as obrigações em matéria de direitos humanos que subsistem caso o referido Estado também denuncie a Carta da Organização dos Estados americanos deve ser ressaltado que o sistema interamericano deve visar à universalidade da ratificação dos instrumentos de direitos humanos, como reflexo de seu caráter universal, indivisível e interdependente. Para a CIDH, a plena observância dos direitos humanos é essencial para a construção de democracias sólidas e inclusivas nas Américas.

A CIDH ressalta que os Estados reconheceram que "a harmonia das Repúblicas Americanas só pode ser efetiva na medida em que o respeito pelos direitos humanos e as liberdades fundamentais e o exercício da democracia representativa sejam uma realidade na esfera interna de cada um deles (CORTE IDH. 2021)". "Esta centralidad del ser humano em el sistema interamericano no es una prerrogativa de los Estados acordada a través de normas convencionales, sino que responde a la naturaleza del indivíduo como sujeto de derecho internacional (CORTE IDH. 2021)".

A CIDH conclui que o indivíduo, independentemente do Sistema que se analise, é sujeito de direitos na ordem internacional, sendo capaz de pleitear perante órgãos internacionais seus direitos. E ainda que a personalidade internacional de um sujeito de direito internacional se mede em função de sua capacidade de ser titular de direitos e deveres internacionais.

A universalização dos direitos humanos é uma aspiração legítima do sistema Interamericano, bem como a sua manifestação de universalidade, indivisibilidade e interdependência.

A CIDH enfatiza que a centralidade do ser humano no sistema interno corresponde a sua posição no direito internacional, e que neste entendimento, como titular dos direitos, reconhecido, o ato e a vontade dos Estados de difundir os sistemas de proteção aos direitos humanos, não implica uma renúncia ao reconhecimento de seus direitos humanos.

Em relação ao terceiro questionamento feito na OC 26/2020, referente aos mecanismos de que dispõe a Comunidade Internacional, em especial os Estados-membros da OEA, para exigir o cumprimento das obrigações, e de outro lado, os indivíduos sujeitos à jurisdição do Estado de exigir a proteção de seus direitos humanos, quando surge um quadro 
de graves e sistemáticas violações de direitos, a CIDH entende que os tratados de direitos humanos são diferentes de quaisquer outros tratados possuem características especiais em razão da matéria.

Os tratados de direitos humanos rompem com as características de obrigações recíprocas, e, portanto, a denúncia a um tratado deve ser discutida não apenas pelo Estado denunciante, mas pelos Estados-membros do Sistema onde o tratado foi denunciado, pelos órgãos da OEA, CIDH, Corte IDH e ainda se tomando em conta o ser humano como sujeito de direitos na esfera internacional.

A Comissão considera que a denúncia de tratados em termos gerais é regida pelas normas estipuladas no referido anexo e, adicionalmente, pelas normas da Convenção de Viena sobre os Direitos dos Tratados. A referida Convenção estabelece em seu artigo 56 que nos casos em que o tratado não preveja denúncia, as regras aplicáveis são as estipuladas no próprio tratado.

\section{CONCLUSÃO}

Os Estados-membros não podem denunciar a $\mathrm{CADH}$ e nem tampouco aos tratados de Direitos Humanos gerados no âmbito do Sistema interamericano de Direitos Humanos porque não há previsão consoante a regra prevista na Convenção sobre Direitos dos tratados, em especial devido as características especiais dos referenciados tratados.

A luz do direito internacional, convencional e consuetudinário, e em especial, a Declaração Americana de Direitos e Deveres do Homem de 1948, persistem as obrigações em matéria de direitos humanos do Estado-membro da OEA que denunciou a CADH, bem como os mecanismos no âmbito do sistema global e regional de proteção dos direitos humanos, levando-se em conta que a pessoa humana é sujeito de diretos na esfera internacional, e não apenas no Sistema Interamericano.

\section{REFERÊNCIAS}

ONU - ORGANIZAÇÃO DAS NAÇÕES UNIDAS. Estatuto da Corte Interamericana de Direitos Humanos. Disponível em http://www.direitoshumanos.usp.br/index.php/CorteInteramericana-de-Direitos-Humanos/ estatuto-da-corte-interamericana-de-direitos-humanos.html. Acesso em 02 de abril de 2021. 
ONU - ORGANIZAÇÃO DAS NAÇÕES UNIDAS. Resolução A/44/159 - Execuções

Sumárias e Arbitrárias. Disponível em http://daccess-ddsny.un.org/doc/RESOLUTION/GEN/NR0/556/41/IMG/NR055641.pdf?

OpenElement. Acesso em 02 de abril de 2021.

CORREIA, Thereza Rachel Couto. Corte Interamericana de Direitos Humanos. Repercussão jurídica das opiniões consultivas. Curitiba: Juruá Editora. 2008. p.p. 117-133.

\section{CORTEIDH.}

Disponível

em

https://www.corteidh.or.cr/sitios/observaciones/oc26/7_comision.pdf. Acesso em 02 de abril de 2021.

CORTEIDH. Disponível em https://www.corteidh.or.cr/docs/opiniones/seriea_26_esp.pdf. Acesso em 02 de abril de 2021. 